\title{
1 Criteria for effective fallow field eco schemes for farmland 2 birds during non-breeding
}

3 Mirjam Rieger ${ }^{1, *}$, Sarah Mailänder ${ }^{1, *}$, Lea Stier ${ }^{1}$, Julia Staggenborg ${ }^{1}$, Nils Anthes ${ }^{1}$

$4 \quad *$ equal contributions

$5{ }^{1}$ Institute of Evolution and Ecology, University of Tübingen, Auf der Morgenstelle 28,

672076 Tübingen, Germany

7

$8 \quad$ mirjam.rieger@yahoo.de

9 sarah.mailaender@posteo.de

10 I.stier@naturpark-bayer-wald.de

11 julia.staggenborg@uni-tuebingen.de

12 Nils.Anthes@uni-tuebingen.de (corresponding author, ORCID 0000-0003-4189-7849)

13 


\section{Abstract}

15 1. Farmland eco schemes implemented under the current Common Agricultural Policy 16 (CAP) of the European Union are often considered ineffective in halting farmland bird 17 declines. Fallow fields, often seeded with dedicated seed mixtures, rate among the more 18 beneficial eco scheme types. Yet, the CAP currently defines no minimum criteria for 19 fallow fields to qualify as eco scheme, likely jeopardizing their potential biodiversity 20 benefits.

21 2. We investigated the attractiveness of four fallow field types established under CAP eco 22 schemes and dedicated bird conservation programs in Southern Germany. Our 2-year 23 surveys on $>100$ fields focused on the non-breeding season, where food limitation can 24 become particularly problematic. We modelled bird incidences also in response to 25 vegetation structure and adjacent landscape features to derive minimum criteria for 26 effective fallow field eco schemes.

27 3. Fallow field types varied only mildly in overall species richness but showed striking 28 differences in the attracted species. Finches in particular tended to preferentially visit 129 year fallow fields, while buntings tended towards 2-year and older field types. 1-year CAP 30 fallows, however, are typically removed before mid-winter, and thus potentially act as a 31 trap to farmland birds and other wildlife.

32 4. The investigated species consistently preferred larger fallow fields with a more 33 differentiated vegetation structure. Placement close to woods and hedgerows positively 34 affected birds inhabiting woodland ecotones, while classic farmland species showed 35 higher incidences on fallow fields embedded in open landscapes.

36 5. 'Policy implications' Our findings call for the ongoing CAP revisions to specify minimum 37 requirements that qualify fallow fields as eco schemes. These should include an at least 38 biennial cycle, a diversification of seed mixtures, standards for fallow field size, and 39 criteria for their placement in the landscape matrix.

40 Keywords: wild bird mixtures, wildflower plots, set aside, Common Agricultural Policy, 41 farmland eco schemes, winter food gap, farmland birds 
bioRxiv preprint doi: https://doi.org/10.1101/2020.10.07.329847; this version posted October 9, 2020. The copyright holder for this preprint (which was not certified by peer review) is the author/funder. All rights reserved. No reuse allowed without permission.

42 


\section{$43 \quad 1$ Introduction}

44 The diversity and abundance of farmland birds across most of Central and Western

45 Europe has severely declined. The European common farmland bird indicator decreased

46 by 57 percent between 1980 and 2016 (EBCC \& Birdlife International 2020). This decline

47 has been linked to the ongoing intensification of farming practices under the Common

48 Agricultural Policy (CAP) of the European Union, whose subsidies primarily scale with farm

49 size and productivity (Donald et al. 2002, Pe'er et al. 2014). While CAP payments also

50 require farmers to implement dedicated eco schemes, their effectiveness to halt or even

51 reverse farmland biodiversity declines has been questioned (Pe'er et al. 2014, 2017).

52 Current CAP eco schemes rest on three components. First, 'Greening' measures in CAP

53 pillar I make $30 \%$ of the direct cross compliance payments to farmers dependent on the

54 assignment of Ecological Focus Areas (EFA) on $\geq 5 \%$ of their arable land. Second, agri-

55 environment-climate schemes (AECS) offer complementary CAP pillar II funding to

56 member states for farmland-related rural development programs to which farmers can

57 voluntarily subscribe. Third, targeted species protection measures through contractual

58 conservation agreements have been developed by most European countries, again co-

59 funded through CAP pillar II. The third component typically includes highly efficient

60 conservation measures but is implemented on small land fractions, only. In Germany, for

61 example, these measures covered approx. $4,000 \mathrm{~km}^{2}$ or $2.4 \%$ of the agricultural area in

622013 (Grajewski \& Schmidt 2015). In contrast, the first two components receive

63 substantial funding (approx. $27 \%$ of the annual EU agricultural budget, Pe'er et al. 2020)

64 and affect $>10 \%$ of the agricultural area in Germany (Zinngrebe et al. 2017), thus offering

65 a potential to support biodiversity at relevant spatial scales. Recent work, however,

66 suggests that $75 \%$ of the eco scheme area implemented under current Greening and

67 AECS regulations employs options such as catch crops, green cover, or nitrogen fixing

68 crops that are considered ineffective for biodiversity support (Nitsch et al. 2017,

69 Zinngrebe et al. 2017, Pe'er et al. 2017).

70 One eco scheme considered generally effective for farmland bird conservation is the

71 designation of fallow fields (here broadly including uncultivated set-aside cropland as well

72 as fields seeded with dedicated 'wild bird' or wildflower seed mixtures). Yet, since 
73 farmland bird species differ in food preferences and the habitat structures they prefer for

74 shelter, plant species composition and the resultant food supply on different fallow field

75 categories can be expected to differently attract or deter particular bird species (e.g.

76 Perkins et al. 2008). Hence, the conservation value of fallow field eco schemes likely

77 varies with the chosen seed mixtures, age since establishment, vegetation structure, and

78 the composition of the adjacent landscape matrix. This perception contrasts to current

79 CAP eco scheme regulations, which offer only a narrow set of prescribed seed mixtures

80 with (mostly short-term) fallow durations and lack minimum quality requirements with

81 respect to size or placement. To enable a target-oriented revision of CAP eco schemes,

82 our study quantified how fallow field type as well as structure and placement

83 characteristics affect farmland bird incidences.

84 Our surveys focussed on the non-breeding season, when energy demands to maintain 85 body temperature and metabolism are particularly high. Food limitation in late autumn 86 and winter can thus substantially affect farmland bird condition and survival (Newton 87 2004, Siriwardena et al. 2008, Siriwardena 2010). The severity of this 'winter food gap' 88 further increased with recent agricultural intensification. For example, enhanced 89 harvesting efficiency and the replacement of seed rich winter stubble fields by winter 90 crops and green manure reduce the availability of leftover cereal grains (Atkinson et al. 91 2002, Moorcroft et al. 2002, Newton 2017). Moreover, the widespread application of 92 herbicides combined with the abolishment of set-aside requirements in the CAP 2008 93 reform reduced the availability of fields rich in weed seeds, and thus a prime foraging 94 resource for granivorous birds (Marshall et al. 2003, Gillings et al. 2010).

95 In winter, fallow fields are well known to meet foraging and shelter requirements of many 96 farmland birds (Gillings et al. 2010, Kasprzykowski \& Goławski 2012, Joest et al. 2016, 97 Dellwisch et al. 2019). Yet, only few studies to date differentiated bird habitat use within 98 the 'fallow' category, i.e. among different types and ages of fallow fields (e.g. Buckingham 99 et al. 1999, Orłowski 2006, Perkins et al. 2008, Birrer et al. 2018). Their findings varied 100 substantially, likely because of differences in the investigated fallow field types, seed 101 mixtures and surveyed regions, calling for further studies to better substantiate decisions 102 about management strategies. Likewise, only few earlier studies investigated effects of 
103 fallow field vegetation structure and placement on bird abundance (e.g., Henderson et al. 104 2004, Stoate et al. 2004).

105 We investigated habitat use across fallow field types of different age and origin in an 106 agricultural landscape of SW Germany. Our findings can inform the ongoing reform of

107 CAP eco schemes for the upcoming funding period, and help conservation practitioners to 108 select particularly suitable fallow land schemes to support their respective core target 109 species.

\section{Methods}

112 We studied habitat use by 17 bird species known to use fallows for foraging or shelter 113 (Tab. 2). These fall into two guilds containing typical inhabitants of woodland ecotones 114 and of semi-open to open farmlands, respectively (Tab. 2). All species except chaffinch, 115 great tit, and blue tit experienced significant population declines in Europe (EBCC \& 116 Birdlife International 2020) and / or Germany (Gerlach et al. 2019) over the past three 117 decades, and nine species are integrated into the European farmland bird index (Tab. 2).

\subsection{Study area}

120 We surveyed nine study areas (A to $\mathrm{H}$ in Fig. 1) at 330-400 $\mathrm{m}$ a.s.l. in an agricultural 121 landscape in the centre of the SW German federal state of Baden-Württemberg. The 122 study region includes floodplain soils in the valleys of the Neckar and Ammer rivers, and 123 highly fertile loess soils on the adjacent plateaus. Most study areas are under intense 124 agriculture, but study areas D, E and I (in Fig. 1) share exceptionally high baseline 125 proportions of organic farming. All areas have seen an increasing establishment of annual 126 fallows under EU CAP regulations, and perennial fallows in the context of governmental 127 grey partridge and corn bunting conservation projects since 2014. 


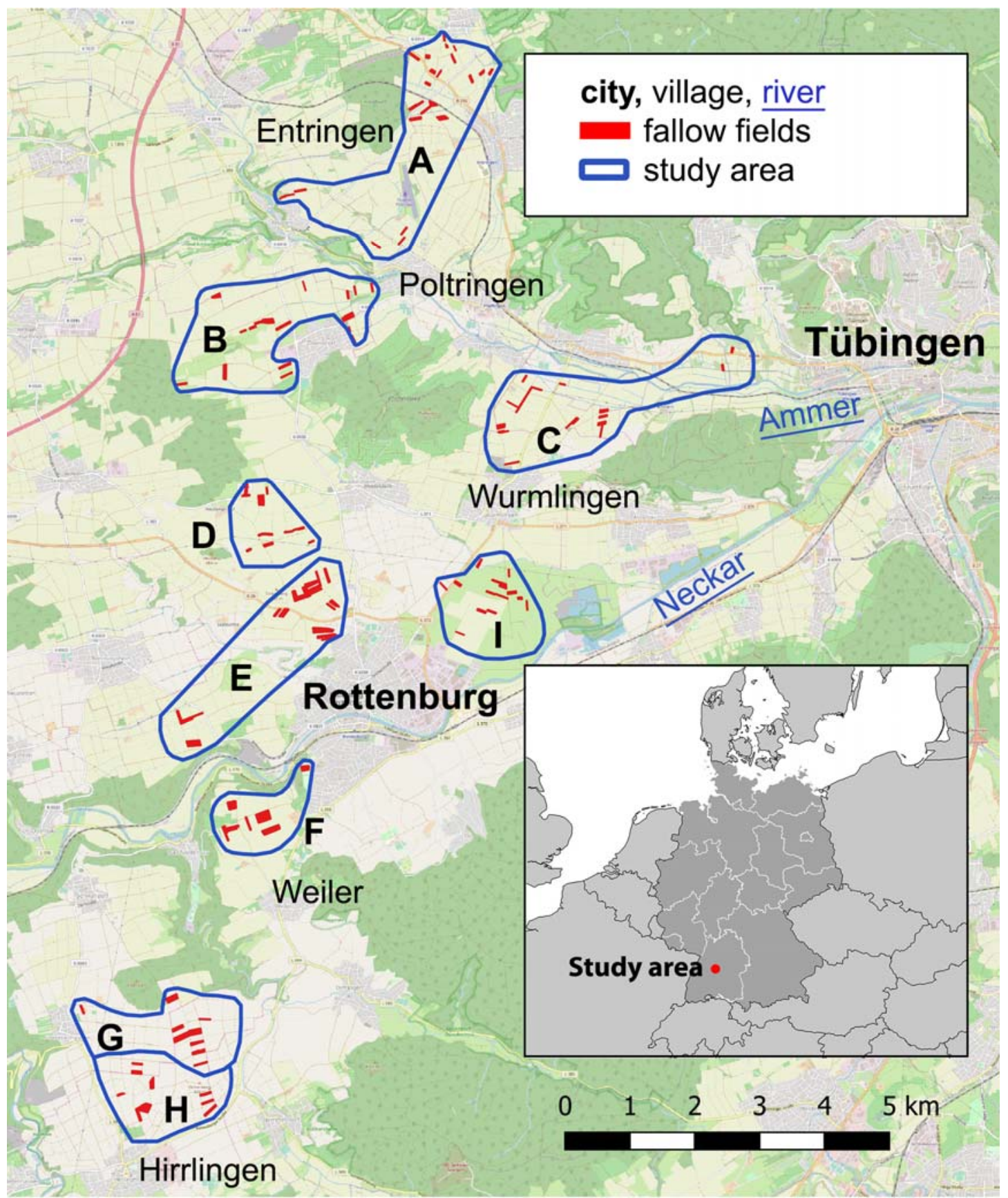

131 Figure 1. Localisation of the nine study areas and all fallow fields investigated in at least one season (sample sizes in Table 1). A - Ammerbuch, B - Oberndorf, C-Ammer Valley, D - Heuberg North, E - Heuberg South, F-Weiler, G - Hirrlingen North, H - Hirrlingen South, I - Neckar Valley. Map source: OpenStreetMap. 


\section{$134 \quad 2.2$ Fallow field types and their characteristics}

135 We distinguished four fallow field types based on seed mixture (details in Online

136 Supplement A) and fallow age, with sample sizes given in Table 1.

137 (i) '1yr-FAKT' subsumes spring-sown annual fallows that qualify as ecological focus areas 138 (EFA) under EU greening regulations, or as a regional eco scheme under the federal 139 government's AECS-program 'FAKT' (BMEL 2015, MLR 2017). Seed mixtures have high 140 shares of annual plants such as sunflower Helianthus annuus, blue tansy Phacelia 141 tanacetifolia, and ramtil Guizotia abyssinica (Fig. 2a). 1yr-FAKT fallows are often removed 142 in September or November (LTZ 2020) to prepare the field for the subsequent winter 143 culture.

144 (ii + iii) 'GM' subsumes fallow fields sown with the so-called Göttingen mixture (GM), a 145 perennial seed mix optimized for grey partridge conservation (Gottschalk \& Beeke 2014). 146 It has a rather balanced mix of annual and perennial plants, usually resulting in 147 structurally rich fields. Yet, dominance may occur by mallow Malva sylvestris and 148 sunflower in year 1, or yellow sweet clover Melilotus officinalis in year 2. GM fallows are 149 implemented via contractual species conservation agreements under the regional 150 Landscape Conservation Directive (Landschaftspflegerichtlinie, Az.: 73-8872.00). In a

151 biennial alternated rotation, half the field is ploughed in winter and newly sown in spring, 152 the other half left untouched until the subsequent winter. Hence, at any time, half the 153 field is in its first year since sowing (1yr-GM, Fig. 2b), the other half in its second year 154 (2yr-GM, Fig. 2c).

155 (iv) '3+yr' subsumes perennial fallows established under a diverse range of conservation 156 activities (Fig. 2d) that were sown at least three years prior to our surveys. Seed mixtures 157 cannot be reconstructed for all those sites, but about half were initially sown with 158 'Lebensraum-I-Tübingen' (Online Supplement A). 3+yr fallows vary in structure and plant 159 composition, but often show high coverage of grasses, teasel Dipsacus fullonum, wild 160 carrot Daucus carota, tansy Tanacetum vulgare and upcoming shrubs. 
161

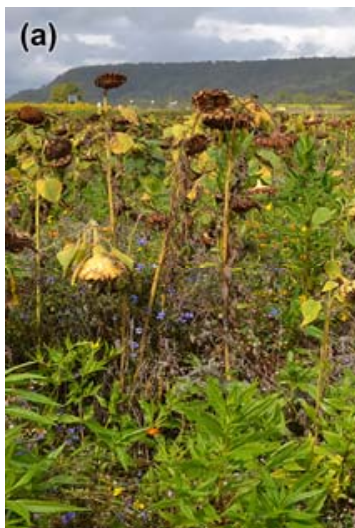

(b)

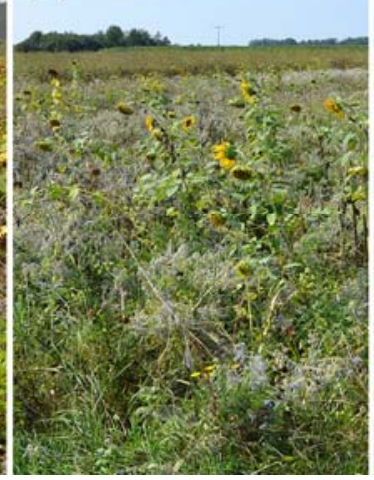

(c)

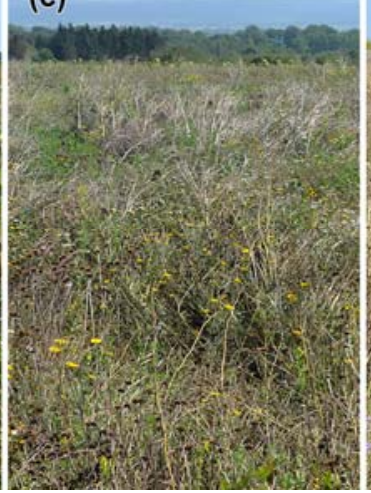

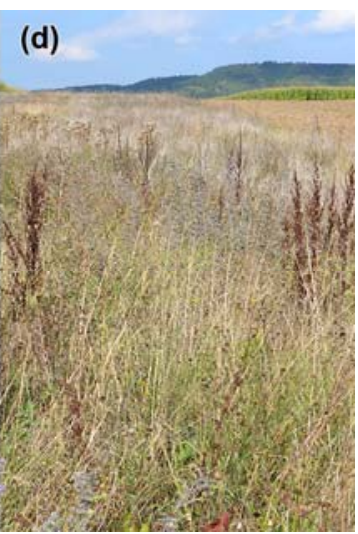

162 Figure 2. Examples of the four surveyed fallow field types: (a) 1yr-FAKT (25 Sep 2019), (b) 1yr-GM (27 Aug 2019), (c) 2yr-GM (30 Aug 2019), (d) 3+yr (11 Sep 2019). Photo (C Sarah Mailänder.

Table 1. Survey periods, the number of replicate surveys, and the number of fields surveyed per fallow field type and investigated season.

\begin{tabular}{lcccc}
\hline & $\begin{array}{c}\text { Autumn 2018 } \\
\text { 21 Aug-25 Sep } \\
\text { 7 surveys }\end{array}$ & $\begin{array}{c}\text { Winter 2018/19 } \\
\text { 03 Jan-16 Feb } \\
8 \text { surveys }\end{array}$ & $\begin{array}{c}\text { Autumn 2019 } \\
\text { 26 Sep-12 Nov } \\
\text { 6 surveys }\end{array}$ & $\begin{array}{c}\text { Winter 2019/20 } \\
\text { 02 Dec-30 Jan } \\
6 \text { surveys }\end{array}$ \\
\hline 1yr-FAKT & 12 & 10 & 37 & 27 \\
1yr-GM & 54 & 42 & 65 & 65 \\
$2 \mathrm{yr}-G M$ & 26 & 6 & 47 & 43 \\
$3+\mathrm{yr}$ & 17 & 17 & 19 & 19 \\
\hline$\Sigma$ & $\mathbf{1 0 9}$ & $\mathbf{7 5}$ & $\mathbf{1 6 8}$ & $\mathbf{1 5 4}$ \\
\hline
\end{tabular}

168 To understand how bird incidence varies with characteristics beyond fallow field type, we 169 recorded the following covariates for each surveyed fallow field:

170 i. Fallow field size (in ha, range 0.06-0.70 ha, with extremes reaching 2.80 ha).

171 ii. Vegetation height (in $10 \mathrm{~cm}$ steps, measuring the dominant vegetation layer).

172 iii. Secondary plant layer (presence/absence), as generated by exposed bud stands of 173 perennials such as sunflower, fennel Foeniculum vulgare or wild teasel, indicating 174 structural diversity.

175 iv. Dominant plant species (presence/absence, with at least 1 species reaching a 176 minimum coverage of $30 \%)$. 
177 v. Bare ground coverage (3 categories: $0-10 \%, 10-30 \%$, and $>30 \%$ of accessible soil 178 representing potential foraging habitat).

179 vi. Farm track (presence/absence) along the longer edge of the fallow field, 180 potentially disturbing roosting birds.

181 Finally, we predicted bird presence to vary with landscape features directly adjacent to a 182 fallow field. We quantified coverage of alternative roosting and foraging structures within 183 a $100 \mathrm{~m}$ buffer around each surveyed fallow field from aerial images (Bing maps) using 184 QGIS version 3.2. From this we derived proportional area coverages for other fallow fields 185 (Fallow coverage) and for hedges, tree clusters and orchards (Hedge and grove coverage).

\section{$187 \quad 2.3$ Bird surveys}

188 Surveys covered autumn and mid-winter periods, each replicated twice in the seasons 189 2018/19 and 2019/20 (Table 1). We recorded the presence and individual numbers of 190 each target species per survey round and fallow field (overpasses ignored). To exclude 191 confounding sequence effects, we randomized starting time, walking direction and the 192 order in which fallow fields were visited across consecutive surveys in a given study area.

193 We spread surveys roughly uniformly across daytimes between 30 min after sunrise and 19430 min before sunset and excluded periods with continuous rainfall or winds exceeding $19540 \mathrm{~km} / \mathrm{h}$. We slowly passed along the long edge of each fallow field, entering it 196 occasionally to also detect birds hiding in the vegetation. To avoid double-counts we 197 visually traced flushed birds to their new location, recording only the fallow field of first 198 encounter. Fields that were mulched or ploughed within a given survey period were 199 excluded when only a single survey had been possible.

\section{$201 \quad 2.4$ Statistical analysis}

202 Statistical analyses for species-specific habitat use per season included all species with > 20310 sightings that spread across at least 15 percent of the visited fallow fields (Table 2). 
Table 2. Number of sites with sightings (\# fields) and total number of sightings (\# obs.) per species per

season. Species in bold face were used for a species-level statistical analysis.

\begin{tabular}{lccccc}
\hline & Autumn & Winter & Autumn & Winter \\
& 2018 & $2018 / 19$ & 2019 & $2019 / 20$ \\
Species & \# fields & \# obs. & \# fields \# obs. \# fields \# obs. \# fields \# obs.
\end{tabular}

(a) Forest ecotone guild

Blue tit Cyanistes caeruleus

- $\quad-\quad 4$

$4 \quad 4$

64

97

29

33

Great tit Parus major

Brambling $^{\mathbf{b}}$ Fringilla montifringilla

Chaffinch Fringilla coelebs

Tree sparrow ${ }^{a}$ Passer montanus

$\begin{array}{cccccccc}- & - & 4 & 4 & 66 & 111 & 23 & 32 \\ - & - & - & - & 27 & 37 & 4 & 5 \\ - & - & 22 & 43 & 81 & 153 & 25 & 35 \\ 48 & 107 & 10 & 22 & 67 & 123 & 15 & 23\end{array}$

(b) Semi-open to open farmland guild

Whitethroat Sylvia communis

Yellowhammer ${ }^{\mathrm{a}}$ Emberiza citrinella

$\begin{array}{cccccccc}22 & 29 & - & - & - & - & - & - \\ 76 & 184 & 21 & 39 & 81 & 113 & 49 & 66 \\ 29 & 44 & 14 & 36 & 36 & 54 & 25 & 33 \\ 48 & 107 & 8 & 12 & 60 & 78 & 14 & 19 \\ 18 & 28 & 10 & 29 & 37 & 42 & 6 & 7 \\ 62 & 148 & 25 & 57 & 78 & 134 & 29 & 34 \\ 30 & 40 & - & - & 6 & 6 & - & - \\ 22 & 32 & 1 & 2 & 15 & 18 & 2 & 2 \\ 33 & 69 & 8 & 11 & 10 & 10 & 2 & 4 \\ 8 & 13 & 1 & 1 & 5 & 7 & - & - \\ - & - & 8 & 10 & - & - & - & - \\ - & - & 11 & 12 & 7 & 8 & 5 & 5\end{array}$

$206{ }^{a}$ species is part of the European farmland bird index (EBCC \& International 2020).

207 b species-level statistical analysis only for autumn.

210 Separately for each bird species, but combined across years for autumn and winter

211 season (Table 1), we modelled bird occurrences using generalized linear mixed models

212 (GLMM). Bayesian estimation procedures used the Stan C++ library as implemented in the

213 rstanarm package version 2.19 .2 (Goodrich et al. 2020) for R version 3.6.2 (R Core Team

214 2017). The response variable in species-level models was derived from the number of

215 surveys with and without recordings (= successes and failures) using the binomial family

216 and a logit-link, resulting in 'bird incidence' as the probability to encounter a species on a 
217 given fallow field. We separately calculated models with the number of sighted species

218 ('species number') as our response variable, now using the Poisson family and a log-link.

219 In all models, fallow field type served as our key predictor variable, with four levels as 220 defined above. The models further contained fixed covariates to account for variation 221 associated with fallow field characteristics beyond field type, as specified in section 2.2. 222 Continuous covariates included fallow field size, fallow coverage, hedge and grove 223 coverage, and vegetation height. The first three of these were $\log _{10}(x+0.01)$-transformed 224 to approach normality, and all four z-transformed prior to analysis. Categorical covariates 225 included farm track presence, secondary plant layer presence, and survey year (2018/19, 226 2019/20). The analysis of winter species numbers further contained survey completeness $227(0 / 1)$ as a covariate, where ' 0 ' identifies $1 \mathrm{yr}$-FAKT and 2yr-GM fallow fields that were 228 ploughed already before the end of our successive surveys. We excluded the covariates 229 bare ground and dominant plant species because of strong covariation with fallow field 230 type.

231 While the combined surveys on a given fallow field per season and year represent our raw 232 data points, these suffer from some degree of spatial non-independence, where fields 233 from the same study area are more likely to be visited by the same local bird population. 234 We therefore added study area ID (Fig. 1) as a random intercept to each model. Study 235 areas without any record of a given species during a particular season were excluded 236 from the analysis. We further included an observation-level random intercept, 237 successfully treating overdispersion (Harrison 2014).

238 We initiated Bayesian models with weakly informative prior distributions (means \pm SD for 239 intercepts $0 \pm 10$ and for coefficients $0 \pm 2.5$, respectively) and used posterior predictive 240 model checking to assess model fit and an adequate representation of observed zero 241 counts. For each model, we ran $10 \mathrm{MCMC}$ chains from which we retained 3000 post242 warm-up samples. We then derived covariate coefficient estimates (means $\pm 95 \%$ credible 243 intervals, $\mathrm{Crl}$ ) from the combined 30,000 posterior samples. From these, we also derived 244 posterior probabilities (so-called Bayes $P$ ) that coefficient estimates - as well as pairwise 245 differences between our four fallow field type levels - exceed 0 . The explanatory power 246 of a given model covariate increases when its posterior probability approaches 0 or 1. 247 Most covariate estimates achieved reliable conversion indicators (Korner-Nievergelt et al. 
248 2015), namely 5000 effective posterior samples (observed min 4344), Rhat values $\leq 1.02$

249 (max 1.002) (Brooks \& Gelman 1998 ), and Monte Carlo standard errors (MCSE) $\leq 2 \%$ of 250 the standard deviation (max 1.5\%). For graphical displays, we extracted model 251 predictions and their $\mathrm{Crl}$ of the predictor of interest for defined values of the remaining

252 model predictors, i.e. continuous covariates set to their sample mean, and factors set to a 253 single level when predicting for covariates (Korner-Nievergelt et al. 2015). 


\section{Results}

255 Out of 17 target species, 16 and 15 were recorded at least once during the autumn and 256 winter season, respectively (Table 2), with clearly higher average species numbers per 257 fallow field in autumn (Fig 3).

258

\section{$259 \quad 3.1$ Fallow field types}

260 Average species numbers varied only little between fallow field types. In autumn, even 261 the strongest contrasts yielded differences in mean species numbers of only 0.7 to 1.3 262 between 1yr-FAKT and 1yr-GM fields versus $2 y r-G M$ and $3+y r$ fields, with substantial 263 overlap in credible intervals (Fig 3a, full statistical detail in Online Supplements B and C). 264 Mean species numbers were clearly lower in winter, and very similar in all four fallow 265 field types (Fig 3b, Online Supplements B and C).

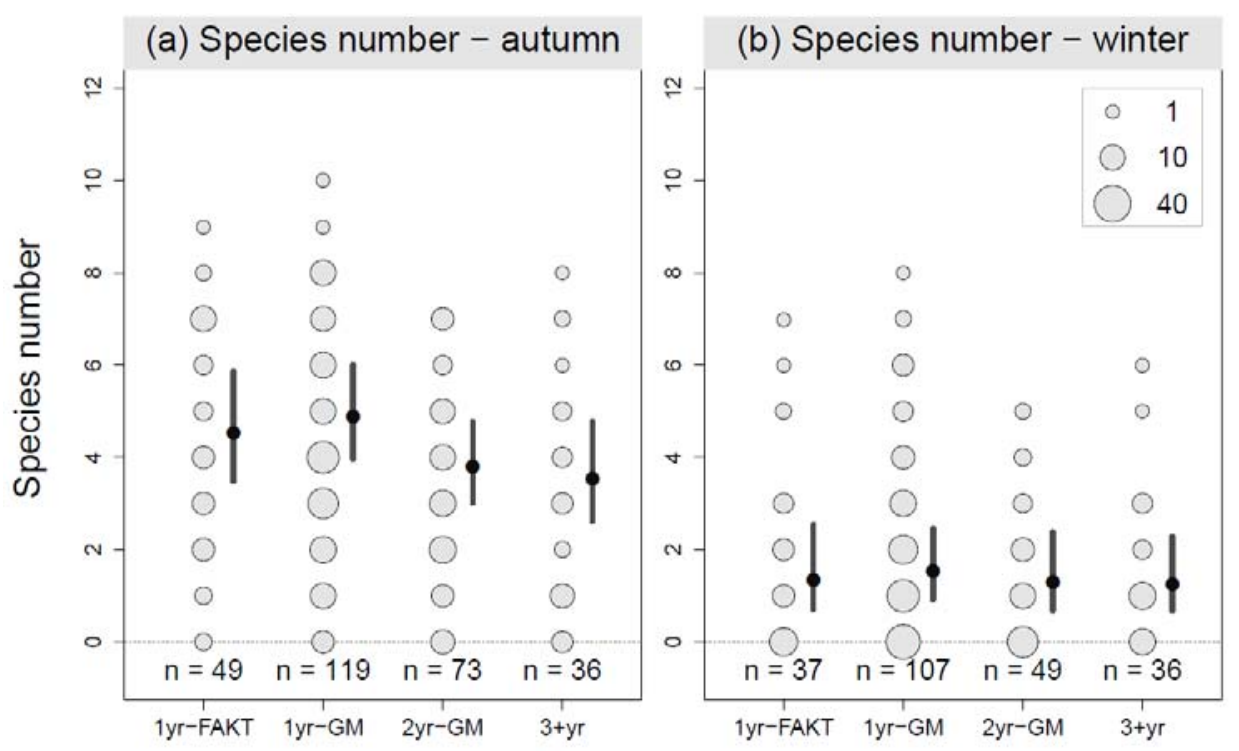

Fallow field type

Figure 3. Observed variation in species number in (a) autumn and (b) winter between fallow field types. Grey dots show raw data and scale with the number of fallow fields. Black dots and flags show modelpredicted means and their $95 \% \mathrm{Crl}$ for the following co-variate levels: survey completeness $=$ yes, year $=$ 2019/20, farm track $=$ no, secondary plant layer $=$ yes. For detailed statistical results, see Online 
273 Individual species exhibited more differentiated patterns in their use of fallow field types.

274 We found a particularly consistent contrast in the usage of 1-year fallow fields (1yr-FAKT

275 and 1yr-GM) compared to later successional stages (2yr-GM and 3+yr), but no further

276 differentiation within each of these two groups. All five surveyed finch species, great tit

277 and tree sparrow - at least in autumn and then coupled with an undifferentiated pattern

278 in winter - showed higher incidences in 1-year compared to older fallow fields, as

279 exemplified in Fig 4a-c (full statistical detail and graphical displays for all study species in

280 Online Supplements B, C, D). The reverse pattern consistently occurred in yellowhammer,

281 reed bunting or whinchat, all showing higher incidences in older fallow fields compared to

282 their first year counterparts (Fig 4d-f, full statistical detail in Online Supplements B, C, D).

(a) Goldfinch - autumn

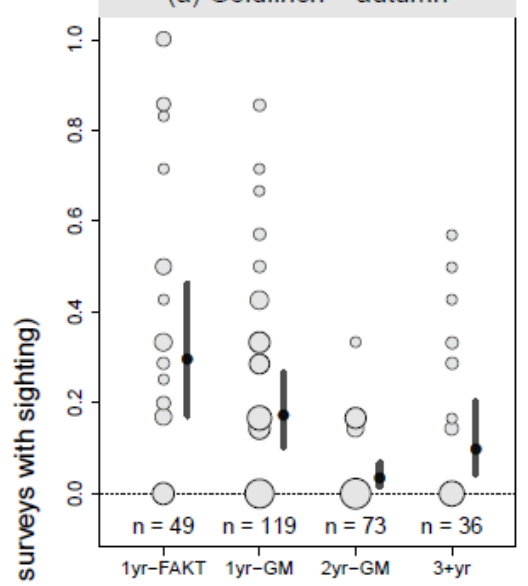

(d) Yellowhammer - autumn

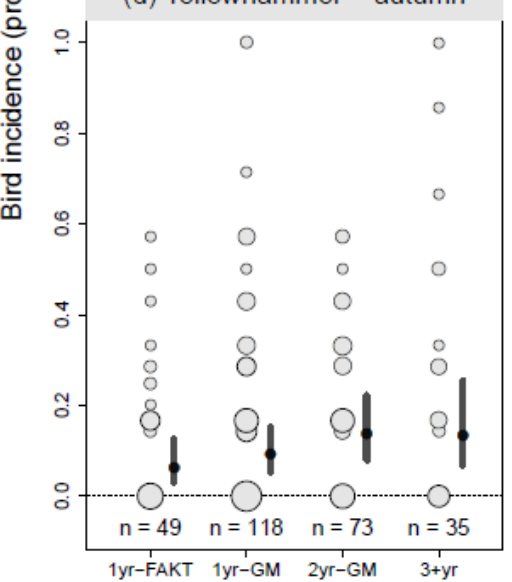

283

284

285

286 (b) Chaffinch - autumn

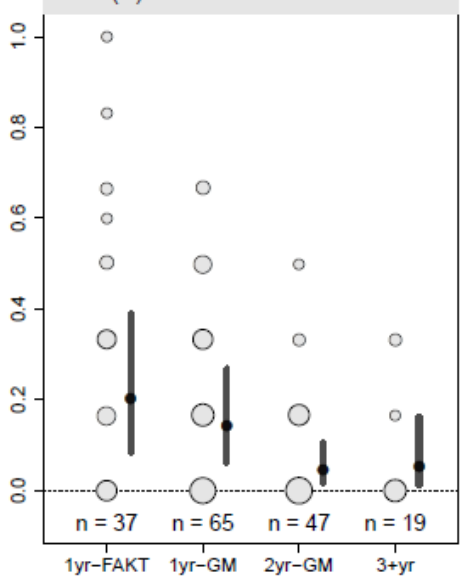

(e) Reed Bunting - autumn

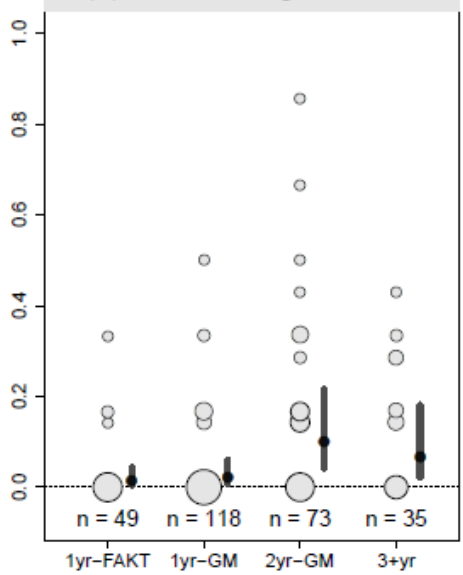

Fallow field type (c) Linnet - autumn

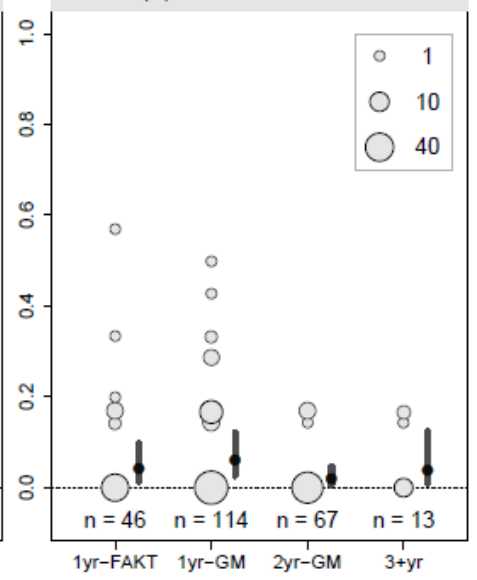

(f) Whinchat - autumn

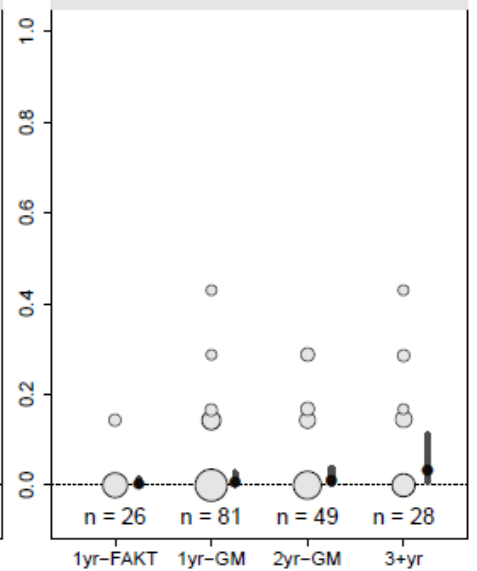

Figure 4. Variation in bird incidences between fallow field types. Examples illustrate strong (goldfinch, a chaffinch, b) and weak (linnet, c) preferences for 1-st year fallows, and strong (yellowhammer, d, reed bunting, e), and weak (whinchat, f) preferences for later successional stages. Grey dots show raw data and 
287 scale with the number of fallow fields. Black dots and flags show model-predicted means and their $95 \% \mathrm{Cr}$

288 for the following co-variate levels: year $=2019 / 20$, farm track = no, secondary plant layer = yes. Detailed

289 results and displays for all study species in Online Supplements B, C, and D.

\section{$291 \quad 3.2$ Fallow field characteristics}

292 Several fallow field characteristics exhibited rather universal co-variation with the total 293 number of recorded species per site as well as species-specific bird incidence. Fallow field 294 size showed a consistent positive, and often strong, relationship with both response 295 measures (Fig 5a). We found similar but slightly more variable positive relationships for 296 fallow fields with taller vegetation ( $F i g$ 5b) and - in particular during winter - for the 297 presence of a secondary plant layer (Fig 5e), indicating benefits to a structurally diverse 298 fallow field vegetation.

299 Contrary to these consistent patterns, species varied strikingly in their predicted response 300 to the availability of hedges and groves nearby fallow fields (Fig $5 \mathrm{c}$ ). While inhabitants of 301 woodland ecotones such as great tit, chaffinch or blue tit tended towards positive 302 responses, farmland birds such as goldfinch, linnet, skylark or stonechat showed higher 303 incidences on fallow fields with little or no hedges and groves nearby, indicating 304 avoidance reactions. Given these differential species responses, overall species richness 305 varied largely independent of this covariate (Fig. 5c).

306 In the majority of cases, the availability of other fallow fields in the near surroundings 307 unfolded no striking correlations with species presence (Fig 5d). Similarly, the presence or 308 absence of a farm track along the long side of a fallow field yielded no consistent patterns 309 with respect to bird presence or species richness (Fig 5f). 


\section{(a) Fallow field size}

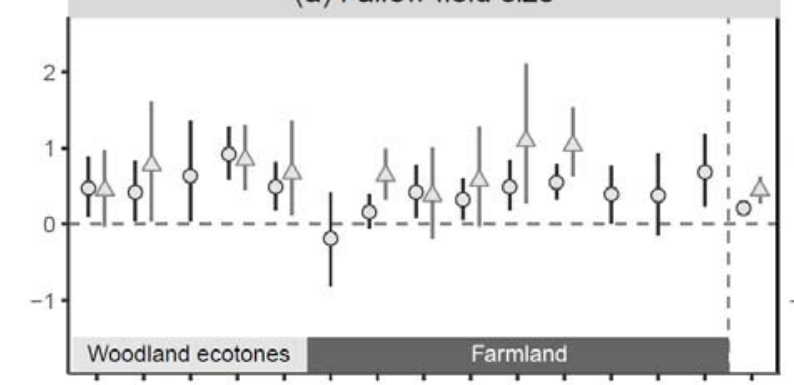

(c) Hedge and grove coverage

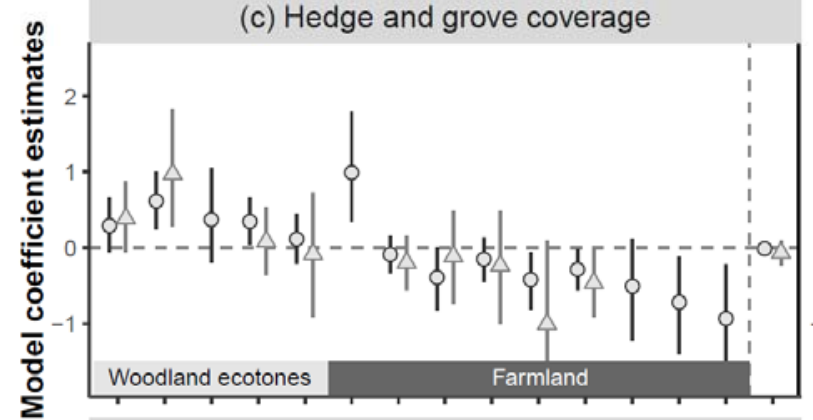

(e) Secondary plant layer

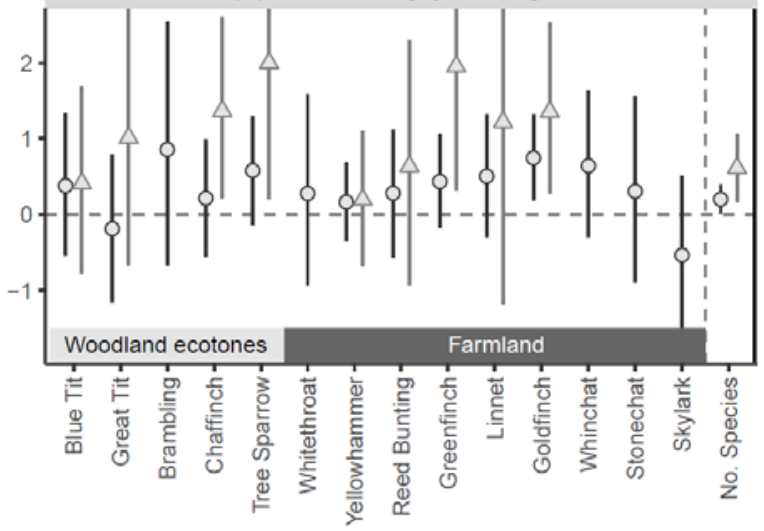

(b) Vegetation height

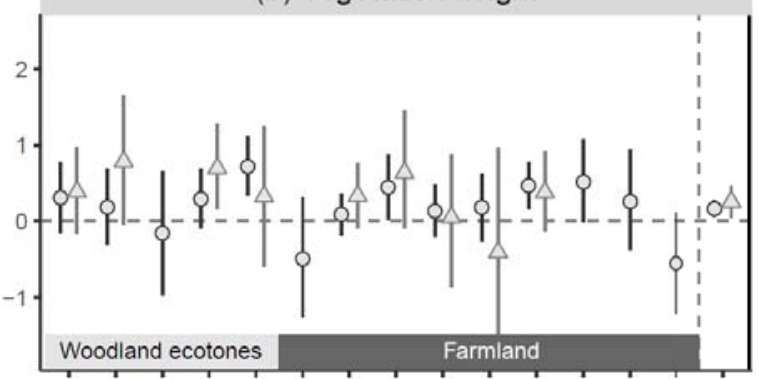

(d) Fallow coverage

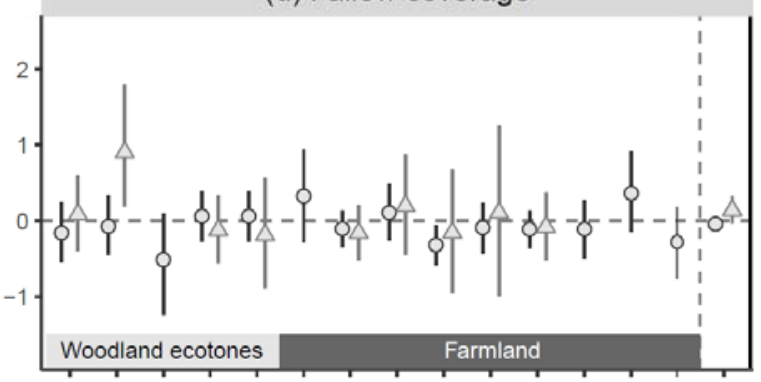

(f) Farm track presence

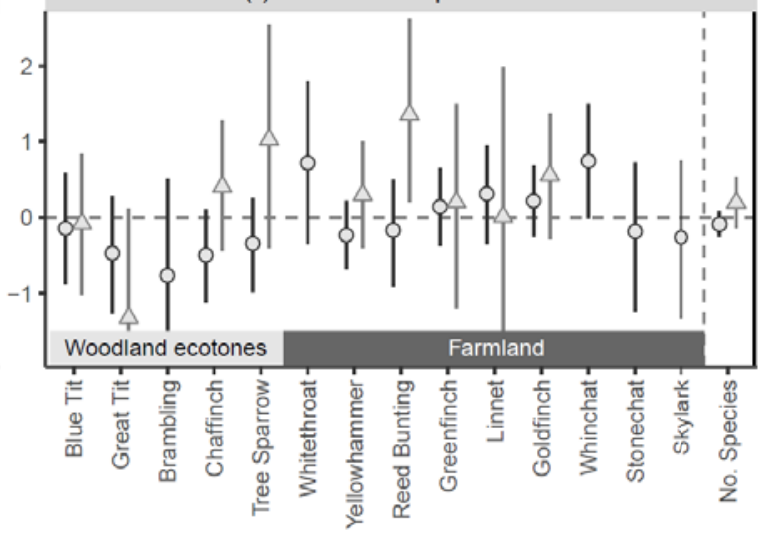

310

\section{Species}

Figure 5. Covariates estimates with their $95 \% \mathrm{Crl}$ for each species, separated by autumn (black circles) and winter (grey triangles) surveys, and grouped by woodland ecotone versus farmland inhabitants. Full coefficient estimates are given in Online Supplement B. 


\section{Discussion}

317 Our study illustrates how fallow field eco schemes differentially support Central European 318 farmland birds. This differentiation did not manifest at the level of overall species 319 richness, which distributed rather uniformly across fallow field types. Instead, we 320 document substantial variation in the degree to which individual species made use of the 321 four investigated fallow field types. The attractiveness of fallow fields further varied 322 strongly with several field characteristics, in particular their size, vegetation structure, and 323 integration into the landscape matrix.

\section{$325 \quad$ 4.1 Fallow field types}

326 A major shift in the supported bird community occurred between 1-year and 2-year and 327 older fallow field types. 1-year fallow fields primarily attracted granivorous birds foraging 328 on large seeds picked from the exposed buds of e.g. sunflowers or bare ground 329 (Henderson et al. 2004), with finches as prime representatives of this guild. 2-year and 330 older fallow fields rather attracted granivores foraging well hidden in the dense and 331 highly structured vegetation on smaller seeds, with buntings as prime representatives.

332 We interpret this pattern to arise from three interacting factors. First, the seed mixtures 333 used in the majority of our investigated fallow fields (Online Supplement A) contain large 334 fractions of - mostly cultivated - annuals that provide many large seeds from, for 335 example, sunflower, borage Borago officinalis or linseed Linum usitatissimum. In their 336 second year, these fields tend to develop clearly lower flowering densities, resulting in 337 lower seedset, with the latter more dominated by perennials such as yellow clover, 338 yellow chamomile Anthemis tinctoria or tansy with rather small seeds. Second, our 1-year 339 fallow fields tended to produce tall stands with little differentiation in vegetation heights 340 and hardly any ground cover by segetal flora or grasses, thus offering only limited shelter

341 for species that preferentially forage in the ground vegetation. This differentiation 342 increases from 2-year onwards, providing suitable habitat structure for a wider range of 343 bird species. Finally, immigrating weeds such as goosefoot Chenopodium album, mugwort 344 Artemisia vulgaris, red-root amaranth Amaranthus retroflexus or thistle Cirsium arvense 
345 increase vegetation differentiation in 2-year and older fallows, and enhance the 346 availability of small seeds.

347 Earlier studies also found diverging winter bird communities between younger and older

348 fallow fields, but differences in the investigated plant compositions and age-classes make 349 comparisons difficult. In Poland, for example, Cirsium-rich young fallows (< 3 years) were 350 preferred by granivores and Tanacetum-rich permanent fallows ( $>3$ years) by insectivores 351 (Orłowski 2006). In Great Britain, skylark, finches and yellowhammer showed more 352 consistent preferences for 1-year than to $\geq 2$-year fallows when compared to other 353 cropland types (Buckingham et al. 1999). In Switzerland, meadow pipit and goldfinch 354 preferred $\leq$ 2-year wildflower strips rich in wild teasel and wild carrot, whereas 355 yellowhammer preferred perennial (14-year on average) fallow fields rich in Rubus shrubs 356 (Birrer et al. 2018).

357 While our data may seem to suggest that 1-year fallows generally represent attractive 358 foraging habitats and thus high quality eco schemes for farmland birds, only 1yr-GM359 types - in stark contrast to 1yr-FAKT-types - can reliably unfold their ecological service. 360 This contrast is rooted in current CAP regulations, which allow 1yr-FAKT type eco schemes 361 to be mown and ploughed already between September and November of the year of 362 sowing (e.g. LTZ 2020). As a consequence, these fallow fields are not available as foraging 363 habitat or shelter during mid and late winter when food restriction culminates 364 (Siriwardena et al. 2008). Such eco schemes may therefore act as a trap for overwintering 365 birds, in particular in arable landscapes that lack local escape options at the time of 366 ploughing. In contrast, GM-type eco schemes are maintained into at least their second 367 year before ploughing, and are then adjacent to a 1-year field section that can act as a 368 local refuge into spring (Gottschalk \& Beeke 2014). This failure of 1yr-FAKT type eco 369 schemes unfolds large scale consequences: Compared to more targeted (and then 370 typically more effective) contractual conservation programs, this scheme alone covers a 371 substantially larger land fraction, in Germany alone approx. $2330 \mathrm{~km}^{2}$ or $1.4 \%$ of the 372 agricultural area in 2019 (DBV 2019). 


\section{$374 \quad 4.2$ Fallow field characteristics}

375 Beyond fallow field type, we found higher overall species richness and incidences of 376 individual bird species on large fields with a tall and structurally diverse vegetation. This

377 implies that eco schemes should prioritize large fallow patches, and seed those with 378 mixtures that develop into structurally diverse and seed rich fallows (see section 4.3). We 379 propose to derive minimum size standards from earlier suggestions that the width of 380 fallow fields should exceed $12-20 \mathrm{~m}$ to minimize predation risks on breeding farmland 381 birds such as Grey Partridge (Bro et al. 2004, Gottschalk \& Beeke 2014). For a field of 150 $382 \mathrm{~m}$ length, this results in minimum fallow field sizes of $0.15-0.3$ ha.

383 The placement of fallow fields within the landscape matrix exhibited species-specific links 384 with bird incidence. Inhabitants of woodland ecotones (Table 2) preferentially visited 385 fallow fields adjacent to (tall) hedges, orchards or groves. This is consistent with earlier 386 findings that many granivores preferentially forage on arable fields along hedgerows, 387 where seed availability is enhanced and shelter nearby (e.g. Robinson \& Sutherland 1999, 388 Stoate et al. 2004, Dellwisch et al. 2019). In contrast, classic farmland birds tended to 389 show higher incidences on fallow fields embedded in a rather open landscape matrix. 390 Avoidance reactions towards woodland-type habitats are well-known for skylark, but 391 have occasionally been documented also for other farmland birds such as goldfinch, 392 linnet and buntings (Parish et al. 1995, Robinson \& Sutherland 1999, Donald et al. 2001). 393 We cannot differentiate whether our observed patterns arise from avoidance reactions or 394 a lower likelihood to observe birds in a given fallow field when they may also just roost in 395 a nearby grove. The latter appears plausible for yellowhammer, greenfinch, and goldfinch, 396 which show lower incidences on fallow fields close to groves in the current study, but 397 have been found to frequently roost in tall hedges in an earlier survey in the same study 398 area (Dellwisch et al. 2019). In summary, fallow fields seem to represent attractive winter 399 foraging habitat irrespective of their placement relative to hedges and groves, but with 400 differences in the supported bird communities. Hence, to serve both requirements, 401 effective eco schemes should assure that fallow fields are not placed solely at marginal 402 yield locations close to forests or tall hedgerows, but also integrated into the widely open 403 agricultural landscape. 
$405 \quad 4.3$ Seed availability, winter food gap and seed mixtures

406 We did not quantify seasonal variation in seed availability in flower heads or soil samples

407 on our study sites. Yet, haphazard surveys of seed loads in sunflowers or teasel imply

408 substantial depletion towards mid-winter, consistent with previous research (e.g.

409 Boatman et al. 2003, Henderson et al. 2004, Perkins et al. 2008, Geiger et al. 2014).

410 Fallow field eco schemes may therefore fail on winter food provision as one of their key

411 goals, with established negative effects on buntings, sparrows, or skylark (Peach et al.

412 1999, Siriwardena et al. 2008). Mitigation can pursue three approaches. First, fallow field

413 eco schemes should explicitly integrate seed mixtures sown in late summer instead of

414 spring, then enhancing chances that annuals set seed late and maintain seed provisioning

415 until late winter.

416 Second, seed mixtures should increase the share of plants that retain seed into late

417 winter. Promising candidate species include kale Brassica oleracea, quinoa Chenopodium

418 quinoa, linseed, triticale Tritico secale or millet, while sunflower, borage, oat Avena sativa

419 or barley Hordeum vulgare deplete seeds already in autumn (Boatman et al. 2003,

420 Henderson et al. 2004, Perkins et al. 2008). This coincides with studies identifying kale,

421 quinoa, linseed and several cereals as particularly relevant food sources for granivorous

422 buntings and finches (Stoate et al. 2003, Henderson et al. 2004, Stoate et al. 2004, Perkins

423 et al. 2008). We propose that these species should partially replace the substantial seed

424 mixture shares of plants with minimal role for foraging farmland birds, such as phacelia,

425 buckwheat or yellow sweet clover (Marshall et al. 2003, Henderson et al. 2004, Perkins et

426 al. 2007), consistent with their representation in wild bird mixtures for the British

427 environmental stewardship program (Boatman et al. 2003).

428 Third, we propose to enhance regional AECS-based funding for unharvested cereal crops

429 (so-called 'seeding cereals' in Henderson et al. 2004), which represent a prime winter

430 food for many granivorous birds. Such cereal-biased options are central to the British

431 environmental stewardship program (e.g. Natural England 2013) and available also in

432 some German Federal States (e.g. Joest et al. 2016), but insufficiently attractive to

433 farmers under the current subsidy system in Baden-Württemberg. Buntings and sparrows

434 in particular profit from the high abundance of cereals, for example on unharvested crop

435 mixtures (Holland et al. 2006, Joest et al. 2016, Perkins et al. 2008). 


\section{$437 \quad 4.4$ Conclusions}

438 This study supports the hypothesis that farmland birds substantially vary in habitat use 439 among available fallow field types, both between species but also between seasons 440 within single species. We suggest that the ongoing CAP reform formulates explicit 441 minimum standards to qualify fallow fields as effective eco scheme options. A large-scale 442 application of just a few types of fallow field seed mixtures and age as supported under 443 current CAP regulations clearly fails to support the full diversity and demands of farmland 444 birds in winter (Hinsley et al. 2010, Redhead et al. 2018). CAP eco schemes should 445 therefore integrate diversification of seed mixtures (in particular to include plants 446 retaining seed into late winter) and successional stages (e.g., 2-year-rotational and 447 perennial) within a local context. While 1-year fallow fields provide attractive foraging 448 habitat, CAP eco schemes need to integrate a biennial cycle as a minimal requirement, 449 with no ploughing before April of year 2 (Siriwardena 2010). Finally, CAP eco schemes 450 need to define minimum standards for fallow field size and criteria for their placement in 451 the landscape matrix.

\section{Authors' contributions statement}

454 NA and JS conceived the study, and jointly with LS, MR and SM designed its methodology; 455 MR, SM and LS collected the data; MR, SM and NA analysed the data; MR, SM and NA led 456 manuscript drafting. All authors contributed critically to the drafts and gave final approval 457 for publication.

\section{Acknowledgments}

460 The exceptional land fractions devoted to farmland bird conservation measures in our 461 study area originates from joined efforts of conservation practitioners (Sabine Geissler- 
462 Strobel and the IAN initiative), local nature conservation and agriculture authorities

463 (Thorsten Teichert, Maik Klingele), and the farmers providing their land. Thanks to Matteo

464 Santon for discussion of the statistical approaches, and to Allan Perkins for comments on

465 an earlier manuscript draft. JS was supported by Stiftung Naturschutzfonds Baden-

466 Württemberg (Az. 73-8831.21/54691-1749L), fieldwork by Carl ZEISS sports optics.

468 Online supplements

469 Online Supplement A. Seed mixtures.

470 Online Supplement B. Bayesian model coefficients.

471 Online Supplement C. Pairwise comparisons between fallow field types.

472 Online Supplement D. Covariate raw data plots for all investigated species.

473 Data available via the Dryad Digital Repository:

474 DOI https://doi.org/10.5061/dryad.1rn8pk0rt

475

476 References

477

478

479

480

481

482

483

484

485

486

487

488

Atkinson, P. W., Fuller, R. J. \& Vickery, J. A. 2002. Large-scale patterns of summer and winter bird distribution in relation to farmland type in England and Wales. Ecography 25, 466-480.

DBV [Dt. Bauernverband] 2019. Greening 2019: Tabelle ÖVF. URL: https://www.bauernverband.de/pressemedien/pressemitteilungen/pressemitteilung/greening-2019-oekologischevorrangflaechen-weiter-auf-stabilem-niveau, last seen 01 Oct 2020.

Birrer, S., Auchli, N., Duplain, J., Korner, P., Lanz, M., Lugrin, B. \& Vasseur, J. 2018. Habitatnutzung der Vögel in einer offenen Kulturlandschaft im Winter. Ornithol. Beob. 115, 11-34.

BMEL [Bundesministerium für Ernährung und Landwirtschaft] 2015. Umsetzung der EUAgrarreform in Deutschland. Ausgabe 2015, pp. 124. 
Boatman, N., Stoate, C., Henderson, I., Vickery, J., Thompson, P. \& Bence, S. 2003. Designing crop/plant mixtures to provide food for seed-eating farmland birds in winter. BTO research report 339.

Bro, E., Mayot, P., Corda, E. \& Reitz, F. 2004. Impact of habitat management on grey partridge populations: assessing wildlife cover using a multisite $\mathrm{BACl}$ experiment. Journal of Applied Ecology 41, 846-857.

Brooks, S. P. \& Gelman, A. 1998. General methods for monitoring convergence of iterative simulations. Journal of computational and graphical statistics 7, 434-455.

Buckingham, D. L., Evans, A. D., Morris, A. J., Orsman, C. \& Yaxley, R. 1999. Use of setaside land in winter by declining farmland bird species in the UK. Bird Study 46, 157-169.

Dellwisch, B., Schmid, F. \& Anthes, N. 2019. Habitatnutzung von Feldvögeln außerhalb der Brutzeit im Kontext der EU-Agrarförderung. Vogelwarte 57, 31-45.

Donald, P., Buckingham, D., Moorcroft, D., Muirhead, L., Evans, A. \& Kirby, W. 2001. Habitat use and diet of skylarks Alauda arvensis wintering on lowland farmland in southern Britain. Journal of Applied Ecology 38, 536-547.

Donald, P. F., Pisano, G., Rayment, M. D. \& Pain, D. J. 2002. The Common Agricultural Policy, EU enlargement and the conservation of Europe's farmland birds. Agriculture, Ecosystems \& Environment 89, 167-182.

EBCC \& Birdlife International 2020. PanEuropean Common Bird Monitoring Scheme: Species trends. https://pecbms.info/trends-and-indicators/species-trends/. Last seen 01 Oct 2020.

Natural England 2013. Entry Level Stewardship-Environmental Stewardship Handbook: DEFRA, UK.

Geiger, F., Hegemann, A., Gleichman, M., Flinks, H., de Snoo, G. R., Prinz, S., Tieleman, B. I. \& Berendse, F. 2014. Habitat use and diet of Skylarks (Alauda arvensis) wintering in an intensive agricultural landscape of the Netherlands. Journal of Ornithology $155,507-518$.

Gerlach, B., Dröschmeister, R., Langgemach, K., Borkenhagen, K., Busch, M., Hauswirth, M., Heinicke, T., Kamp, J., Karthäuser, J. \& König, C. 2019. Vögel in Deutschland Übersichten zur Bestandssituation. DDA, BfN, LAG VSW, Münster.

Gillings, S., Henderson, I. G., Morris, A. J. \& Vickery, J. A. 2010. Assessing the implications of the loss of set-aside for farmland birds. Ibis 152, 713-723.

Goodrich, B., Gabry, J., Ali, I. \& Brilleman, S. 2020. rstanarm: Bayesian applied regression modeling via Stan.: R package version 2.19.2, https://mc-stan.org/rstanarm. . 
524 Gottschalk, E. \& Beeke, W. 2014. Wie ist der drastische Rückgang des Rebhuhns (Perdix 525 perdix) aufzuhalten? Erfahrungen aus zehn Jahren mit dem Rebhuhnschutzprojekt 526 im Landkreis Göttingen. Berichte zum Vogelschutz 51, 95-116.

527 Grajewski, R. \& Schmidt, T. G. 2015. Agrarumweltmaßnahmen in Deutschland - Förderung 528 in den ländlichen Entwicklungsprogrammen im Jahr 2013: Thünen Working Paper 529 44. doi: 10.3220/WP1440484615000.

530 Harrison, X. A. 2014. Using observation-level random effects to model overdispersion in count data in ecology and evolution. PeerJ 2, e616.

532

Henderson, I., Vickery, J. \& Carter, N. 2004. The use of winter bird crops by farmland birds in lowland England. Biological Conservation 118, 21-32.

Hinsley, S. A., Redhead, J. W., Bellamy, P. E., Broughton, R. K., Hill, R. A., Heard, M. S. \& Pywell, R. F. 2010. Testing agri-environment delivery for farmland birds at the farm scale: the Hillesden experiment. Ibis 152, 500-514.

Holland, J. M., Hutchison, M. A. S., Smith, B. \& Aebischer, N. J. 2006. A review of invertebrates and seed-bearing plants as food for farmland birds in Europe. Annals of Applied Biology 148, 49-71.

Joest, R., Kamrad, M. J. \& Zacharias, A. 2016. Vorkommen von Feldvögeln auf verschiedenen Nutzungstypen im Winter - Vergleich zwischen nicht geernteten Getreideflächen, Brachflächen, Stoppeläckern und Flächen mit Zwischenfrüchten. Vogelwelt 136, 197-211.

Kasprzykowski, Z. \& Goławski, A. 2012. Habitat preferences of granivorous passerine birds wintering on farmland in eastern Poland. Bird Study 59, 52-57.

Korner-Nievergelt, F., Roth, T., von Felten, S., Guélat, J., Almasi, B. \& Korner-Nievergelt, P. 2015. Bayesian Data Analysis in Ecology Using Linear Models with R, BUGS, and Stan. London: Academic Press.

LTZ [Landwirtschaftliches Technologiezentrum Augustenberg] 2020. Informationen zu ackerbaulichen Maßnahmen in FAKT und Greening - April 2020. URL: https://ltz.landwirtschaft-bw.de. - Funding programme for environment, climate protection and animal welfare Baden-Württemberg. Stuttgart. abundance. Journal of Applied Ecology 39, 535-547. 
561 Newton, I. 2004. The recent declines of farmland bird populations in Britain: an appraisal of causal factors and conservation actions. Ibis 146, 579-600.

Newton, I. 2017. Farming and Birds. Collins New Naturalist Library: HarperCollins UK.

564

565

566

567

568

569

570

571

572

573

574

575

576

577

578

579

580

581

582

583

584

585

586

587

588

589

590

591

592

593

594

595

596

597

Nitsch, H., Röder, N., Oppermann, R., Milz, E., Baum, S., Lepp, T., Kronenbitter, J., Ackermann, A. \& Schramek, J. 2017. Naturschutzfachliche Ausgestaltung von Ökologischen Vorrangflächen. Endbericht zum gleichnamigen F+E-Vorhaben (FKZ 35148241 00). BfN-Skripten 72, 1-194.

Orłowski, G. 2006. Cropland use by birds wintering in arable landscape in south-western Poland. Agriculture, Ecosystems \& Environment 116, 273-279.

Parish, T., Lakhani, K. \& Sparks, T. 1995. Modelling the relationship between bird population variables and hedgerow, and other field margin attributes. II. Abundance of individual species and of groups of similar species. Journal of Applied Ecology 32, 362-371.

Pe'er, G., Bonn, A., Bruelheide, H., Dieker, P., Eisenhauer, N., Feindt, P. H., Hagedorn, G., Hansjürgens, B., Herzon, I. \& Lomba, Â. 2020. Action needed for the EU Common Agricultural Policy to address sustainability challenges. People and Nature 2, 305316.

Pe'er, G., Dicks, L. V., Visconti, P., Arlettaz, R., Báldi, A., Benton, T. G., Collins, S., Dieterich, M., Gregory, R. D., Hartig, F., Henle, K., Hobson, P. R., Kleijn, D., Neumann, R. K., Robijns, T., Schmidt, J., Shwartz, A., Sutherland, W. J., Turbé, A., Wulf, F. \& Scott, A. V. 2014. EU agricultural reform fails on biodiversity. Science 344, 1090-1092.

Pe'er, G., Lakner, S., Müller, R., Passoni, G., Bontzorlos, V., Clough, D., Moreira, F., Azam, C., Berger, J. \& Bezak, P. 2017. Is the CAP Fit for purpose? An evidence based fitness-check assessment: Leipzig, German Centre for Integrative Biodiversity Reserach (iDiv) Halle-Jena-Leipzig.

Peach, W. J., Siriwardena, G. M. \& Gregory, R. D. 1999. Long-term changes in over-winter survival rates explain the decline of reed buntings Emberiza schoeniclus in Britain. Journal of Applied Ecology 36, 798-811.

Perkins, A. J., Anderson, G. \& Wilson, J. D. 2007. Seed food preferences of granivorous farmland passerines. Bird Study 54, 46-53.

Perkins, A. J., Maggs, H. E. \& Wilson, J. D. 2008. Winter bird use of seed-rich habitats in agri-environment schemes. Agriculture, ecosystems \& environment 126, 189-194.

Redhead, J., Hinsley, S., Beckmann, B., Broughton, R. \& Pywell, R. 2018. Effects of agrienvironmental habitat provision on winter and breeding season abundance of farmland birds. Agriculture, Ecosystems \& Environment 251, 114-123.

Robinson, R. A. \& Sutherland, W. J. 1999. The winter distribution of seed-eating birds: habitat structure, seed density and seasonal depletion. Ecography 22, 447-454. 
598 Siriwardena, G. M. 2010. The importance of spatial and temporal scale for 599 agri-environment scheme delivery. Ibis 152, 515-529.

600 Siriwardena, G. M., Calbrade, N. A. \& Vickery, J. A. 2008. Farmland birds and late winter 601 food: does seed supply fail to meet demand? Ibis 150, 585-595.

602 Stoate, C., Henderson, I. G. \& Parish, D. 2004. Development of an agri-environment 603 scheme option: seed-bearing crops for farmland birds. Ibis 146, 203-209.

604 Stoate, C., Szczur, J. \& Aebischer, N. J. 2003. Winter use of wild bird cover crops by 605 passerines on farmland in northeast England. Bird Study 50, 15-21.

606 R Core Team 2017. R: A language and environment for statistical computing. $R$ 607 Foundation for Statistical Computing. Vienna, Austria. URL: http://www.R$608 \quad$ project.org/.

609 Zinngrebe, Y., Pe'er, G., Schueler, S., Schmitt, J., Schmidt, J. \& Lakner, S. 2017. The EU's 610 ecological focus areas - How experts explain farmers' choices in Germany. Land 611 Use Policy 65, 93-108.

612 